\title{
GIANT PARATHYROID ADENOMA WITH SEVERE HYPERCALCEMIA CASE REPORT
}

C. SPIROIU ${ }^{1}$, A. E. RANETTI ${ }^{1}$, A. MAZILU ${ }^{1}$, C. NISTOR ${ }^{2}$

CENTRAL UNIVERSITY EMERGENCY MILITARY HOSPITAL “CAROL DAVILA “ BUCHAREST, ROMANIA

1 - DEPARTMENT OF ENDOCRINOLOGY; 2 - DEPARTMENT OF THORACIC SURGERY

Introduction:

Parathyroid adenomas are the main cause of primary hyperparathyroidism. They are usually small - less than $1 \mathrm{~g}$ - and not easy to find - requiring meticulous imaging studies for localization. Giant adenomas (defined according to gland size at or above $3.5 \mathrm{~g}$ - the 95th percentile of gland weight) have seldom been described in the literature.

\section{Case Report:}

- A 68 year old woman presented in our clinic with polydipsia, polyuria, nausea, weight loss, dorsal and lumbar spine pain, extreme muscular weakness - she wasn't able to walk - confusion and depressive mood. Symptoms developed progressively during the last 6 months in a patient with unremarkable medical history. 'Clinical exam: signs of dehydration and a palpable right cervical mass.

Blood chemistry results: serum calcium

$21 \mathrm{mg} / \mathrm{dL}$ (normal range $8.8-10.2$ ), serum alkaline phosphatase 680IU/L(normal range 50-136), serum phosphate $2.0 \mathrm{mg} / \mathrm{dL}$ (normal range $2.5-4.5$ ), normal kidney function. Serum intact PTH was $2238 \mathrm{pg} / \mathrm{mL}$ (normal range 15-65). The patient was also vitamin D deficient - $25 \mathrm{OH}$ vitamin D $14 \mu \mathrm{g} / \mathrm{L}$. Thyroid function tests were normal.

- Radiographic study showed signs of vertebral osteoporosis and fracture of the first lumbar vertebra. Cerebral CT scan (indicated by the psychiatrist) showed multiple osteolytic areas of the skull.

-DXA osteodensitometry: osteoporosis (lumbar spine T score $-2.9 \mathrm{SD}$, radius $33 \% \mathrm{~T}$ score $-6.7 \mathrm{SD}$ ).

Abdominal ultrasound: bilateral nephrolityhiasis.

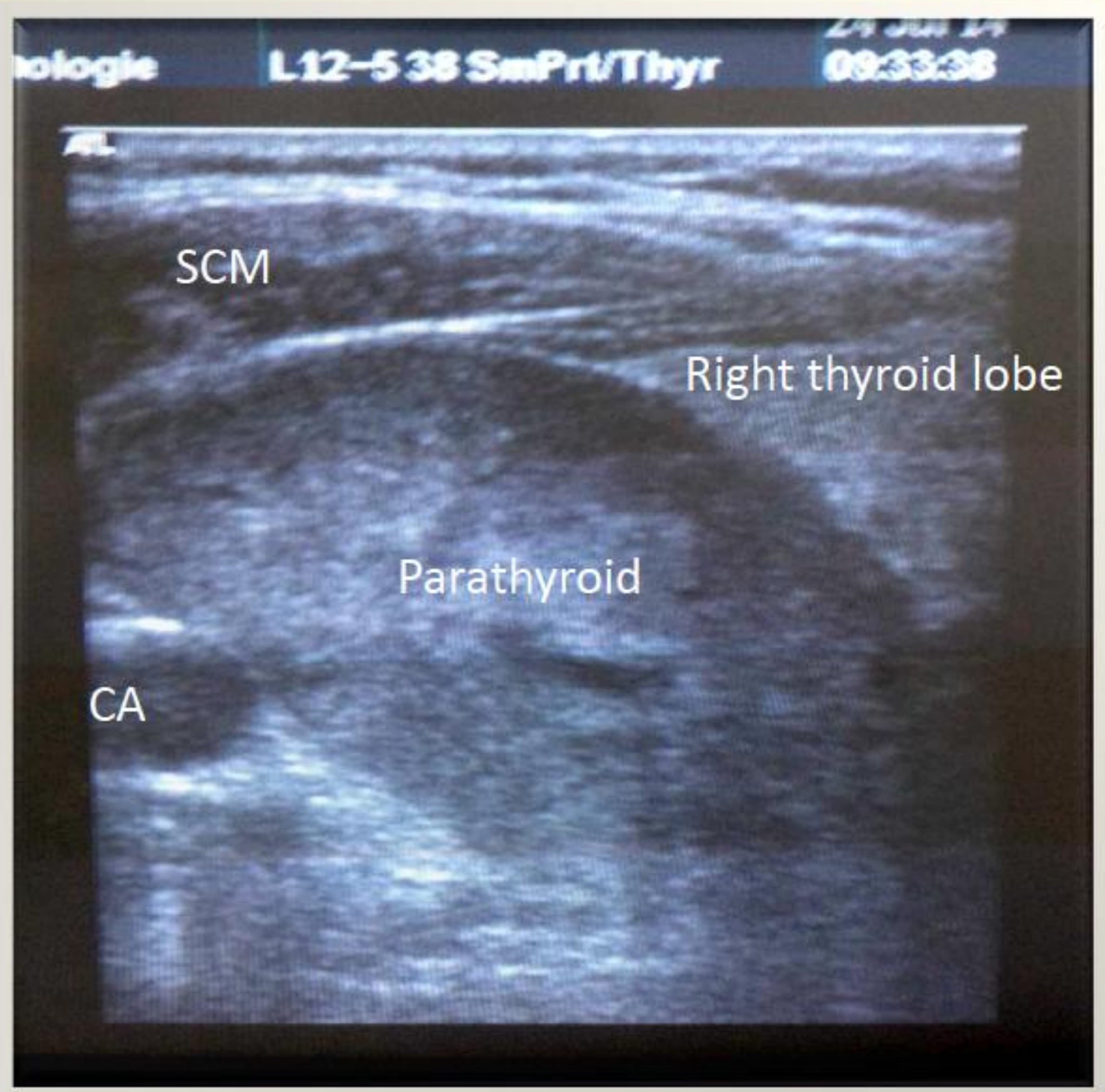

Cervical utrasonography

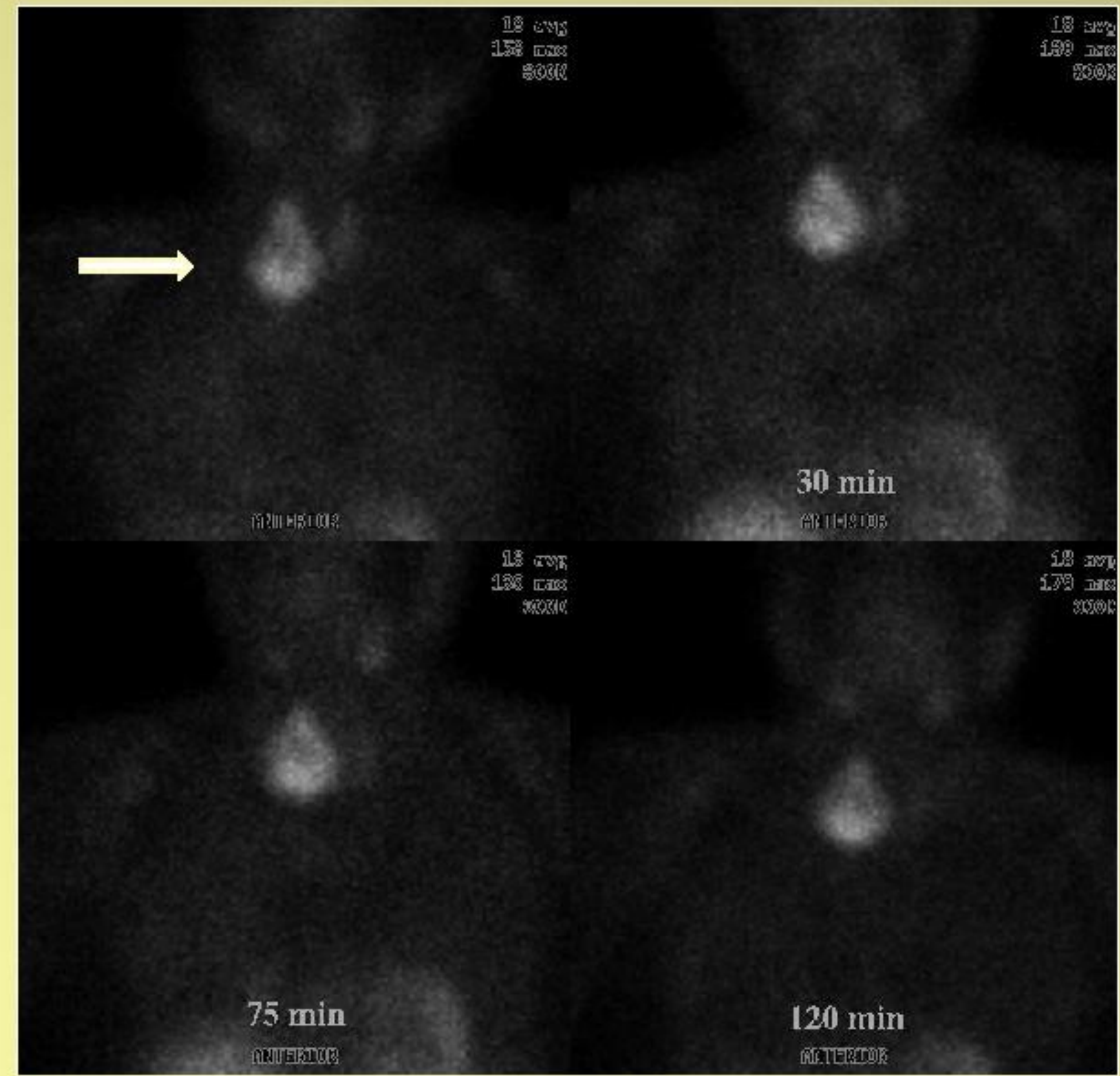

Parathyroid scintigraphy

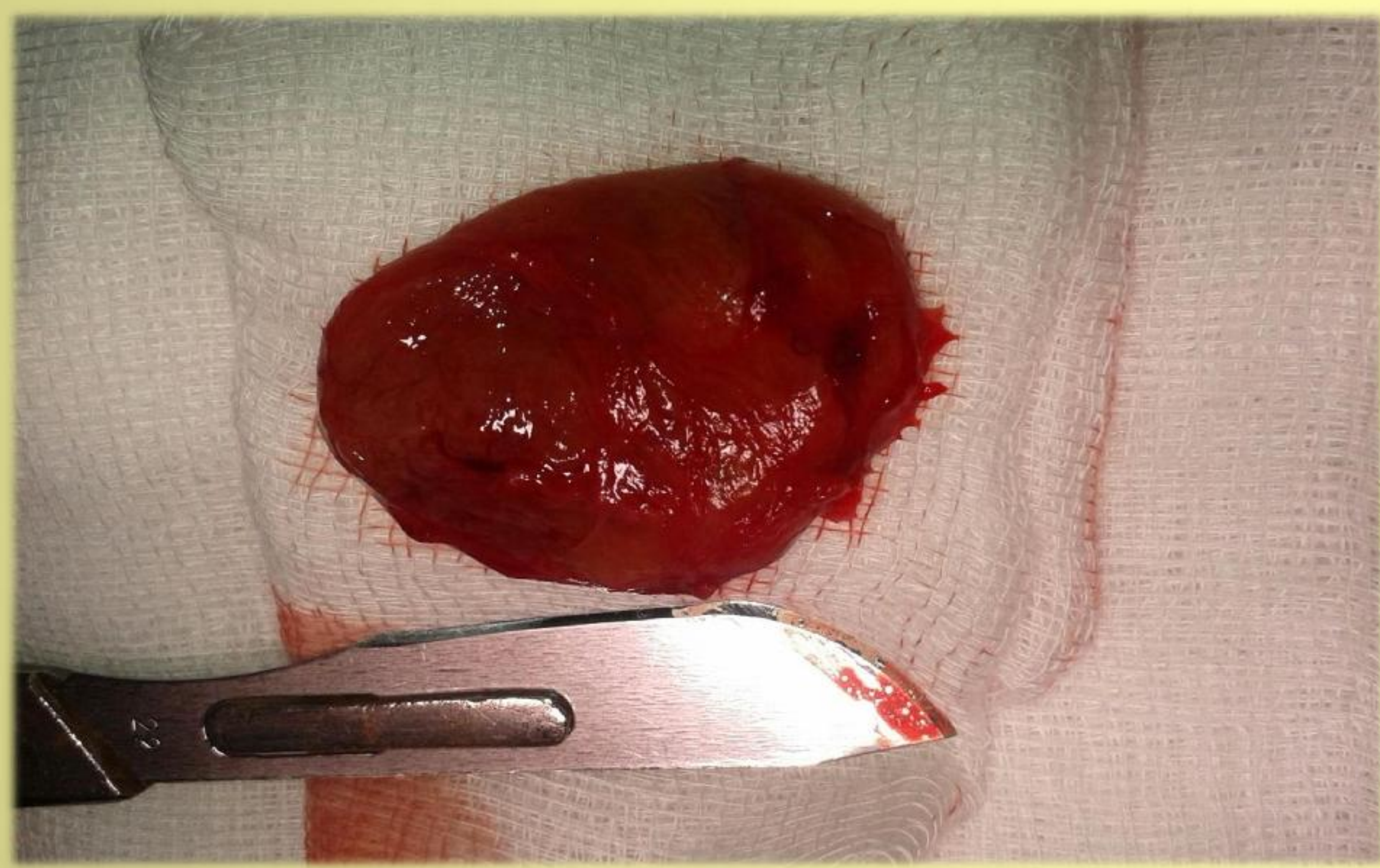

-Cervical utrasonography: hypoechoic, inhomogeneous mass with regular margins, 38/30/45 mm, laterally and caudally to the right thyroid lobe; no image of adenopaty.

- Parathyroid scintigraphy (99Tc-MIBI): large area of high uptake in the right cervical region.

-Treatment : intravenous fluids for re-hydration, loop diuretic (furosemide), intravenous bisphosphonate (Zoledronate $4 \mathrm{mg}$ ) and subcutaneous Calcitonin $(400 \mathrm{U}$ every $12 \mathrm{~h}$ ) to reduce the level of calcium, which decreased to $11.2 \mathrm{mg} / \mathrm{dl}$ after 5 days but did not normalize.

-The patient was successfully operated. Surgical exploration found no evidence of malignancy: the tumor, although large $(32 \mathrm{~g})$, was encapsulated, with no signs of local invasion and was easily removed.

The pathologic diagnosis: parathyroid adenoma with nuclear atypia, without capsular or vascular invasion.

Serum calcium dropped after surgery - lowest level $6.8 \mathrm{mg} / \mathrm{dl}$ fourth day. Hypocalcemia was managed with iv calcium and Alpha-calcidol ( $2 \mu \mathrm{g}$ ). At discharge the patient was hypocalcemic but asymptomatic.

Calcium metabolism parameters - evolution after parathyroid surgery

\begin{tabular}{|c|c|c|c|c|}
\hline & $\begin{array}{c}\text { Calcium } \\
\text { mg/dl } \\
\text { (n 8.8-10.2) }\end{array}$ & $\begin{array}{c}\text { Alkaline phosphatase } \\
\text { IU/I } \\
\text { (n 50-136) }\end{array}$ & $\begin{array}{c}\text { PTH } \\
\text { pg/ml } \\
\text { (n 15-65) }\end{array}$ & $\begin{array}{c}25-O H \text { Vitamin D } \\
\mu g / l \\
(n>30)\end{array}$ \\
\hline At discharge & 8.3 & 678 & 182 & $14.0^{*}$ \\
\hline 1 month & 7.4 & 233 & 506 & 17.2 \\
\hline 3 months & 8.5 & 156 & 390 & 20.5 \\
\hline 6 months & 8.8 & 135 & 62 & 38.0 \\
\hline
\end{tabular}

*preoperative value

Despite treatment with Cholecalciferol $10000 \mathrm{U}$, Calcium $2 \mathrm{~g}$ and Alpha-calcidol $2 \mu \mathrm{g}$ (with close monitoring of calcium metabolism parameters), mild hypocalcaemia persisted for months thereafter and so did the high levels of PTH - the hungry bones syndrome. Parathyroid hormone normalized after 6 months, when calcium and vitamin D levels returned to

\section{Conclusions:}

This is a rare case of giant parathyroid adenoma. The particularities of the case are the size of the tumor, the very high level of calcium and PTH , and the persistence of high levels of PTH and hypocalcemia months after surgery in a patient who is also vitamin D deficient. 